\title{
On Attack and Defense Training in Teaching Basketball
}

\author{
Zhang Jian \\ Civil Aviation Flight University Of China \\ GUANG HAN, CHINA \\ e-mail:name@xyz.com
}

\begin{abstract}
With the increasing popularity of basketball, more and more students are joining professional basketball training activities, and how to effectively develop and implement basketball teaching has already become an issue worthy pondering over and exploring into for basketball teachers and coaches in colleges and universities. The author believes that first of all, students' basic skills should be enhances, and secondly, emphasis should be put on cultivating students' consciousness of basketball while stressing attack and defense training to improve students' basketball skills and cultivate their accomplishments in basketball. Details introduction is made in this paper.
\end{abstract}

\section{Keywords- basketball teaching; attack; defense training}

As it is known to all that basketball is a sport. With the popularity of basketball, especially in the United States, the NBA in the professional league in the world, basketball has been more and more popular, especially for the majority of young people. In the situation of basketball sports is so hot, how to carry out effective basketball teaching in physical education colleges and universities, has become the issue needing to be considered by school sports teachers and coaches [1]. Basketball is a sport loved by the people, from the point of view of the characteristics of basketball itself. It consists of two important aspects of offensive and defensive. However, in some unprofessional basketball fans can see in daily basketball course, most people tend to focus on the offensive, also is shot, while ignoring the defense, the offensive and defensive phenomenon, affecting improving basketball skills. Combining with the teaching experience of college sports basketball, the author discusses the attacking and defensive tactics in basketball teaching process from the following aspects.

\section{ENHANCE BASIC SKILLS AND LAY A SOLID FOUNDATION}

Any sport has some certain requirements for basic skills, so is basketball. With good basic skills, students can better improve their basketball skills. The author believes that to enhance students' basic skills should start from the following two aspects:

\section{A. Exercise Students' Physical Strength}

Consolidate students the basic skills of basketball, first of all should pay attention to strengthen the training of students' body quality. With the continuous development of basketball, basketball is more and more towards intelligence, high speed, accurate, and smart, strong, such as direction, these to student's physical quality had higher demand [2]. The good physical quality, is fundamental to students to master basketball skills. In training students' physical quality, teachers want to notice according to the age characteristics of students, students play style and students' body function, etc., different levels of training arrangements. In general, the athletes' physical quality training for teenagers, teacher or coach should pay attention to training the athletes' flexibility, sensitivity, etc., and other training is auxiliary training content; for the adult athletes, the teacher or coach should pay attention to training the athletes' strength, endurance, spring, and speed, etc., other training content in arrange quantity can be reduced. At the same time, in the process of training, should pay attention to the overall arrangement, give prominence to the training emphasis and so on, still have to pay attention to strict requirements of athletes, and athletes insist for a long time to exercise.

\section{B. Enhance Students' Basic Skills and Pay Attention to Teaching Students according to Their Aptitude}

Basketball technique is the basic of basketball tactics, the use of any tactics, cannot be separated from the players to grasp the degree of basketball technology and its specific application level. Usually case, basketball player must master the technology of mobile, passing, catching, grab the ball, netball, personal defense, center technology and so on. Teachers or coaches should pay attention to strengthen the students' basketball skills, practice good basic skills, so that players continue to improve their basketball skills and the ability to use tactical flexibility. At the same time, a teacher or a coach in training shall pay attention to teaching students in accordance with their aptitude, depending on the level of each athletes, focus on the training. During training, pay attention to the training plan and the improvement of the level of athletes training, and gradually increase the difficulty of training and density, and gradually improve the level of students' basic skills.

\section{CUltivate BASKetball CONSCIOUSNESS AND IMPROVE COMPREHENSIVE QUALITY}

Because of its own characteristics, the basketball sport has a high demand on the athlete's height, weight and body function. However, basketball and other sports, as well as the requirements of the intelligence is also higher. NBA basketball star Steve Nash is famous, who is not strong, not big burly. However, he had to assist into his specialty, makes him a great influence in the NBA. To sum up the reason of this situation can be found, mainly because of Nash has a higher basketball consciousness. The so-called basketball consciousness, refers to the basketball players in the sport, through the brain's thinking, can play a certain 
rule to make their own right judgments and reaction, it is through long-term practice, the refined out of a correct psychological and physiological reaction of a certain kind of ability [3].

Basketball is a team cooperation project, in the movement of any tactical coordination, all the players need to have a good basketball consciousness, therefore, basketball teachers or coaches, in teaching, pay attention to the training of athletes' basketball consciousness:

\section{A. Improve Basketball Consciousness in Watching Games}

Basketball coach or teacher can regularly organize students to watch some good basketball games, letting them feel some of the outstanding athletes in the competition for basketball technology through observation, which improves students' basketball consciousness. The main basketball consciousness includes: the sense of attack, defense consciousness, passing consciousness, and so on. Teachers should pay attention to allow students in the process of watching the game, repeatedly try to figure out and deliberation of excellent athlete's basketball consciousness, and in the actual basketball, will realize the consciousness, placed on his body, and to improve their own level of basketball.

\section{B. Learn Theoretical Knowledge and Improve Basketball Consciousness}

Like others sports, basketball also needs the support of relevant theories. Students learn theoretical knowledge through basketball, can improve students 'literacy, but also help improve students' basketball skills. Therefore, teachers or coaches in their daily training, to focus on theoretical knowledge into them, so that students master the basic theoretical knowledge of basketball tactics, techniques and other aspects of basketball and improve their basketball literacy.

\section{Improve Comprehensive Quality in Basketball Practice}

After learning a large number of theoretical knowledge, the basketball teacher or coach should pay attention to the students to learn the theoretical knowledge of the application in actual combat, and constantly improve the level of students' basketball. Therefore, teachers or coaches should pay attention to the combination of theoretical knowledge and actual combat. Specifically, teachers or coaches should pay attention to provide students with the game or other forms of competition, so that students in practice, learn to observe and understand the opponent, to master the skills to win the game, step by step to improve their actual combat level, continuous improvement.

\section{ATTACK TRAINING}

Basketball is a sport which requires teamwork to win. In the game, how to win the team, in every link to win, is every member of the basketball game should be considered. To do a good training is an important part of the basketball game, The author starts from the following aspects:

\section{A. Understand Tactical Requirements}

As is known to all, the basic tactic of basketball is to solve the contradiction between the two persons in the attack and defense. At the same time, the basketball tactics of the flexible use of individual basketball skills and the cooperation between the members of collocation, has a higher requirement. The main goal of basketball tactics is to play each member's expertise, restrict each other, in the course of the game, to fight for the initiative, to win. In general, whether offensive or defensive tactics, by technology, methods, forms of these three parts. Technology is the basic of tactics, but also an indispensable part of basketball, and the method is the main content of tactics, but also the core of tactics. As for the form, it is the external manifestation of basketball tactics, that is, through a certain form to show the basketball technology. And for the offensive side of the training, teachers or coaches, to focus on training student's pass, chipping, sudden, cover, attack, attack zone press, the offensive zone and so on [4]. Therefore, to improve the students' offensive tactics, the tactical requirements must be firstly understood .

\section{B. Improve Attack Effects}

With the continuous development of basketball, it is found that the requirements of basketball is also more and more high. And a large number of facts have proved that a good point guard, to protect the normal operation of the team. Therefore, to improve the team's offensive efficiency, that is, the whole team is to lead the team in the lead, to form an organism. Each member should be as the same as the machine parts, coordination and cooperation, while minimizing mistakes, to improve the team's offensive efficiency.

\section{Accurately Apply Fast-Attack Technique}

The so-called fast attack technique, refers to is when team members to get the ball, defensive into offensive, with the fastest, shortest time beyond the opponent, in terms of the number of formation to make the situation of the minority to the majority of people, or in a balanced number of, in other stable before the defenders, the quick fit way to attack. This attack, mainly in order to fight for the time, to create a fighter. The more active compared at present, fast break, this kind of attack is the basketball team generally use the tactics, and positional warfare. Therefore, teachers or coaches in the training of the students of offensive tactics can let students strengthen the fast break training and improve the students' level of operations.

\section{ATtACK AND DEFENSE TRAINING}

Like attack in basketball, defense is also an important link in basketball. In general, the basketball defense mainly by the defensive basic skills, personal defense, collective defense, defensive tactics and so on. The author carries on a detailed discussion on the defensive training as follows:

\section{A. Focus on Training Basic Defense Skills}

Defensive basic skill is an important aspect of basketball tactics. Basic skills include defensive slide, running, step back and so on. Do a good job in defense of the basic skills, first of all, teachers or coaches have to focus on training students' physical quality, including the ability to balance exercise students that students in sliding or running, the body is able to ability to maintain the balance. Students in fast venue and movement speed faster, 
when an opposing player emergency stop, students can quickly stop. At the same time, in the process of defense, in the face of a strong opponent, athletes should have a strong physical quality, to have the strength and the other side to compete, for example, the other side of the jump, athletes should have a flexible body reaction ability and strength of its intervention.

\section{B. Strengthen Students' Individual Defense Training}

In basketball, personal defense is mainly divided into Anti-ball players and anti-ball players. The main defensive task for a ball player is to try to interfere with or destroy the opponent's shooting action or other aggressive action. When the opponent in close to the basket or some of the most dangerous areas, the defenders of the important task is to fully interference each other's shooting, will focus on the opponent to shooting hand, trying to interfere with his hand, reduce the hit rate of shooting each other. At the same time, for different circumstances, to take a different defensive strategy. For example, opponents in low risk region, the defender to in case as a key breakthrough, try to each other keep distance, after stopping the opponent, to prevent each other have the opportunity to pass or shoot [5]. Also in the case of a ball players to pay attention to the use of defensive feint, such as intentionally relaxes distance to divert attention and so on, and then seize the opportunity, the hidden ball. But without the ball against the athletes, mainly to prevent the ball in an important position. Moving without the ball defensive players, the main form of cross cutting, slitting. In the presence of crosscutting, should pay attention to in advance, resist, and slitting, they should immediately stepped forward, to resist. Similarly, anti - ball players, still need to be based on the actual situation, to take the appropriate measures. Basketball teachers or coaches should pay attention to strengthen the development of the game, so that students in practice to improve their ability to defend.

\section{Pay Attention to Collective Defense}

Collective defense is based on personal defense, good personal defense can make collective defense better play its role. Teachers in the teaching to grasp student's collective defense training, pay attention to anti complement, rotations, around the front, confining grab center, attack and other aspects of training, improve the athlete's collective defense ability.

- Filling-in, a relatively common defense in basketball. This method is mainly used in some of the breakthrough force is very strong forward or back, suddenly rushed to the basket, then you need to make up filling-in. Filling-in method has the implementation of closure and blocking its path form, not let the other hand.

- Switch, mainly used in conditions in which the opposite side has poor attack ability. At this moment, rotation athletes can timely be forward blocking, in relief, beware of foul, attention moves quickly and accurately.

- Go around the front to grab the center. The tactics are commonly used in collective defense tactics, in the other side of the center near the basket, to focus on the former defense; and when the other center is away from the basket, athletes should stand in front of the other side, and when the other side after receiving the ball, the team should immediately go to grasp for it.

- Attack and closing. The main purpose is to attack each other, let the other outgoing ball or unauthorized mistakes. Attack should pay attention to grasp the opportunity, for example, in the midline, the bottom line of the defensive player let other stopping, the team with the athletes should immediately come to attack [6]. And the door is closed, the other is a breakthrough, athletes and other players to move closer, as opponents of the barriers to create a line break.

- Go around, cross and squeeze. Athletes are to keep up with their own team of athletes, in the time, the action to quickly, and choose the best path; athletes in the time to wear, to advance and players in language contact; and squeeze the time, the action to be fast.

\section{Enhance Training of Defense Strategies}

Defensive tactics is a higher level of basketball defense, which requires the mutual cooperation between individual and collective. Basketball defensive tactics, mainly in the three cases, audience of people marking, half court man to man defense, and a zone defense. Any of these tactics, the main purpose is to effectively resist the attack. In the actual game. Defensive tactics often need according to the site, to make corresponding adjustment, sometimes playing zone defense will suddenly become a man to man defense, and sometimes in play half court man to man defense, very can instantly become a full court man to man defense [7]. Defensive tactics, the main is to disrupt the rhythm of the other side of the attack, for their team to win the fighter. Teachers in the defensive training of athletes, the practice of sports should be strengthened, so that students continue to sum up the experience and improve the students' ability to use the defensive tactics.

\section{E. Cultivate Sportsmen's Defense Consciousness}

Defense is an important part of the basketball game, and it has an important guarantee for the team's attack. Therefore, defensive awareness shall be trained in the daily physical training of basketball players.

Defensive consciousness is a kind of psychological activity, which is a reflection of the athletes' activities on the field. The main defensive consciousness includes the consciousness of the ball players, the consciousness of the players, the consciousness of the players and the consciousness of the flexible use of tactics. Teachers or coaches to strengthen the defensive training of students, is conducive to the athletes in the actual game, the rapid attack and defense conversion, so as to win the fighter.

\section{CONCLUSION}

An excellent team should not only have outstanding attack capacity, but also prominent defense capacity. Therefore, in daily basketball training, teachers or coaches should strengthen training both in attack and defense for sportsmen. Adolescents are in the golden period for growth, physically and mentally, so teachers should follow the changing rules of basketball based on sportsmen's own characteristics to conduct scientific and effective training 
towards students, constantly improving students' basketball techniques and accomplishments to make great contributions for the nation in producing excellent basketball players.

\section{REFERENCES}

[1] Wei Fanqi. Analysis of Attack and Defense Training in Teaching Basketball [J]. Cultural and Sports Facility and Technology, 2015,(8):174-174,176.

[2] Lv Lianqiang. Attack and Defense Training in Teaching Basketball [J]. Weekly Journal of Exam, 2014,(2):113-114.
[3] Zhao Guanglong. On Attack and Defense Training in Teaching Basketball [J]. Knowledge Economy, 2015,(5):130.

[4] Liu Mingci, Wang Ziqiang. On Defense in Basketball [J]. Journal of Henan College of Finance and Taxation, 2011, 25(6):79-80.

[5] Yu Fei. On Basketball Defense Teaching and Training [J]. Heilongiiang Scientific and Technological Information, 2010, (36):217.

[6] Wang Wenkai. On Issues Needing Emphasizing in Basketball Teaching and Training [J]. Scientific and Technological Information, 2013,(26):319.

[7] Ma Feng. Discussion of Modern Basketball Attack Defense Teaching and Training [J]. Journal of Changchun Institute of Education, 2014,(7):102-103. 